\title{
A Perspective on Algae, the Environment, and
}

\section{Energy}

\author{
Phillip E. Savage ${ }^{a}$ and Jamie A. Hestekin ${ }^{b}$ \\ ${ }^{a}$ Department of Chemical Engineering, University of Michigan, 3074 HH Dow, Ann Arbor, MI, 48109; psavage@umich.edu (for \\ correspondence) \\ ${ }^{b}$ Ralph E. Martin Department of Chemical Engineering, University of Arkansas, Fayetteville, AR 72701
}

Published online 2 September 2013 in Wiley Online Library (wileyonlinelibrary.com). DOI 10.1002/ep.11847

\begin{abstract}
Aquatic biomass, in general, and algae, in particular, are gaining attention for wastewater treatment and as a feedstock for renewable fuels. Research into algae biofuels is receiving significant attention because of the potential for providing high amounts of fuel with low land use. Several obstacles still remain especially in the area of algae selection, bioreactor choice, conversion to fuel precursors, and ultimate fuel production. This special issue of Environmental Progress and Sustainable Energy focuses on these issues and recent work that moves the field toward environmentally sustainable algae production. () 2013 American Institute of Chemical Engineers Environ Prog, 32: 877-883, 2013

Keywords: algae, biofuels
\end{abstract}

\section{INTRODUCTION}

Aquatic biomass, in general, and microalgae, in particular, hold tremendous potential for addressing issues at the energy-environment nexus [1]. Aquatic plants can be used to perform environmental services such as wastewater treatment [2], phytoremediation [3], and $\mathrm{CO}_{2}$ removal from flue gas [4]. The accumulated biomass can then be used as a feedstock for the production of renewable fuels. Research into the use of algae as a feedstock for biofuels has grown rapidly in recent years [4]. In fact, as shown in Figure 1, a Web of Science search on the topics "algae" and "biofuels" revealed a growth in articles from 5 in 2006 to 356 in 2012. Some of the biggest reasons for this explosion of interest in algal biofuels are the extremely fast growth rate of algae, the high amounts of oil that algae can contain, the ability of algae to grow on marginal land, and the thousands of strains that allow for growth potential in many different climates. A comparison between the growth rates of algae and switchgrass, another second generation biofuel feedstock, revealed that providing half the liquid fuel needs in the United States would require $1.1 \%-1.7 \%$ and $60 \%-108 \%$ of the total U.S. crop land for algae and switchgrass, respectively [5]. This huge reduction in the amount of land required as opposed to other feedstocks is a source for optimism, but significant challenges to full-scale implementation remain. These challenges include: identifying the optimum algae strains for fast growth and high yield, identifying the best way to grow algae, identifying the ideal methods to extract the useful components from algae, and identifying the most effective fuel/product mix and how algae can effectively be converted to this product

(C) 2013 American Institute of Chemical Engineers mix at scale. This issue of Environmental Progress and Sustainable Energy provides insight on the cutting edge of each of these four different areas of development necessary for sustainable full-scale algae production. This perspective article, though not a complete review, provides an overview of this special issue and gives the authors' views on current research and what needs to be done to further develop algal biorefineries.

\section{ALGAE SELECTION}

There are several steps involved in screening species for their algae-to-fuel potential. A few of these steps are summarized in Figure 2. As shown in the figure, the first step is to select a target species for characterization. This species would ideally have a high growth rate, produce high concentrations of a desirable product mix, and have low cost media requirements. Many times, this initial species selection is based on targeting species from nature that have been shown to be dominant in mixed culture, grow under extreme conditions, or store high amounts of lipids. A detailed review on selecting a culture for biodiesel production is given by Griffiths and Harrison [6]. In this study, the authors compare the two major deciding factors in algae selection for that application: growth rate and lipid production. In many cases, algae have the highest concentration of lipid when grown under nitrogen-depleted conditions, although often this approach requires sacrificing growth. However, algae strains such as Amphorea and Ettila oleoabundans have high lipid content even in nitrogen-replete environments leading to lipid productivities at or greater than $150 \mathrm{mg} / \mathrm{L}$ day [6].

The preceding paragraph illustrates that an important factor (outlined in Figure 2) is selecting growth conditions. As algae grow in many different environments, the same strain of algae can give low to high oil content depending on the growth conditions. Welter et al. [7] found that Scenedesmus dimorphus could range in lipid content from 2.2\% to $28 \%$ just by varying the $\mathrm{NaNO}_{3}$, or nitrogen content. Zhao et al. [8] used a bio-oil as a feedstock supplement for algae growth and found that at only a $4 \%$ level, this bio-oil significantly enhanced the rate of $\alpha$-linoleic acid (18:3) production. These examples show how important it is to select appropriate growth conditions even after a species is identified, as the growth environment can affect the amount and type of products being produced.

Another important factor in the selection of growth conditions is the rate of nutrient addition and ways to recycle 


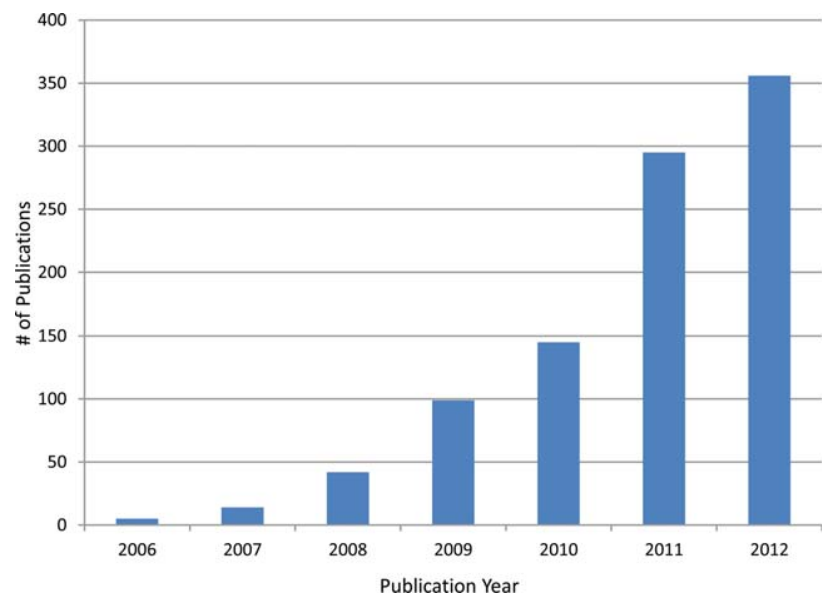

Figure 1. Citations by year from a web of science search of "algae" and "biofuels." [Color figure can be viewed in the online issue, which is available at wileyonlinelibrary.com.]

these nutrients. Pate et al. [9] discussed approaches using nonpotable water, thereby helping to reduce nutrient requirements. This choice of how to recycle the nutrients can transform a process from extremely environmentally friendly to completely unsustainable. Fortunately, there are several approaches to reduce the amounts of the mined or chemically synthesized nutrients required for algae growth. Jernigan et al. [2] have explored a pilot option using the Rockaway Wastewater Treatment Plant in New York, New York as the nutrient source in algae growth. This approach allows the algae to provide the environmental service of wastewater treatment while simultaneously obviating the need for mined or synthesized nutrients. Wang et al. [10] used water hyacinth for phytoremediation in Canada. These two approaches are among those that recognize that "pollutants" in one context can be alternatively viewed as nutrients to enhance algae growth. Another approach, especially attractive in a photobioreactor system, is to recycle nutrients directly from the algae processing scheme back into algae growth. Levine et al. [11] recycle nutrients released during hydrothermal formation of biochar back to the photobioreactor for algae growth. Cherad et al. [12] use water and the nutrients released from supercritical water gasification of aquatic biomass and found that as long as nutrient levels did not get too low, algae growth could be supported. All these approaches are important as they show that algae can use nutrients in nominal waste streams and in some biorefinery process water streams.

To properly select an algae strain for biofuels, several different factors must be considered. These include its growth under nutrient-rich and deprived environments, whether the nutrients can be recycled, what effects changes in nutrients and environmental factors have on product distribution, and the growth rate and lipid content of the algae cells. Work et al. [13] examined the many factors in algae communities that can direct metabolism. To drive algae research forward, the traditional approach of selecting only the highest growth strain must be reconsidered.

\section{REACTOR TYPE}

The type of reactor to be used for algae growth is another important consideration that accompanies setting up a large scale algae growth system. There are three basic choices (which are summed up in Table 1): photobioreactor, open pond, and Algal Turf Scrubber ${ }^{\mathrm{TM}}$. All three of these choices have distinct advantages and disadvantages. A photobioreactor offers controlled conditions and thus typically has the

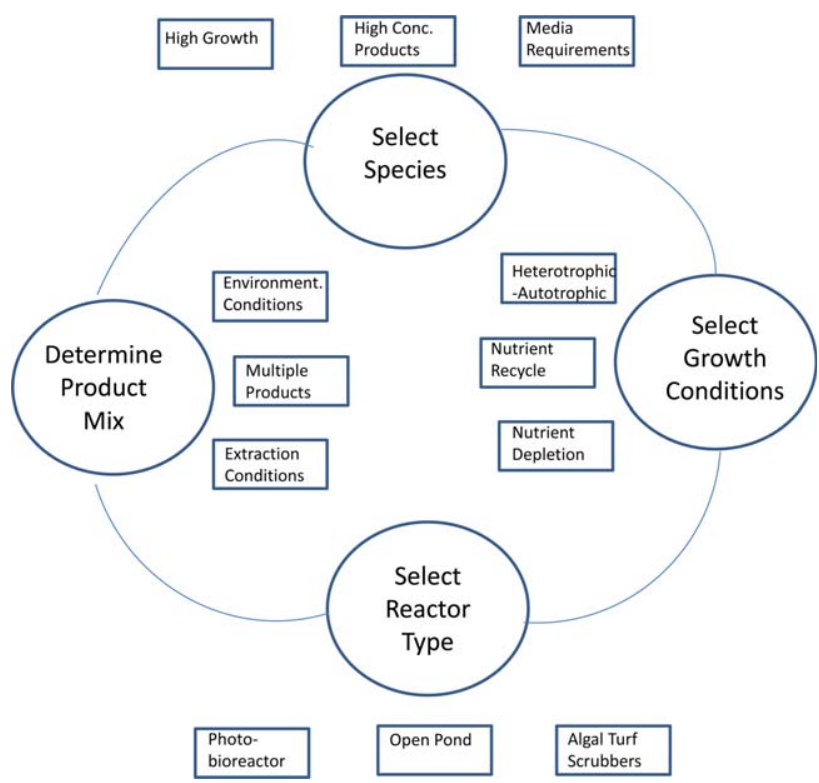

Figure 2. Factors influencing the selection of an algae growth process. [Color figure can be viewed in the online issue, which is available at wileyonlinelibrary.com.]

highest growth production potential and facilitates maintaining an algal monoculture. However, it is often difficult to provide enough light for phototrophic growth, and the capital costs of photobioreactors are typically the highest. Solazyme cultivates algae for biofuels in a heterotrophic bioreactor in which light does not need to be introduced [14]. Kong and Vigil [15], in this special issue, use a Taylor vortex photobioreactor to introduce a flashing light effect thereby driving up the growth rate. Algenol Biofuels [16] uses clear plastic bags to make sealed bioreactors for ethanol production. Furthermore, much research is going on to make photobiorectors more productive [17] and more cost effective [18].

The second type of algae growth system is the open pond. The open pond has the advantages of being simple to use and control and typically being less expensive than a bioreactor. However, the growth rate is typically not as high as in a photobioreactor and contamination of an algal monoculture by invasive species is a risk. Sapphire Energy [19] is using open ponds on a several acre scale in a desert environment to grow algae for their "green crude." Strum and Lamer [20] have shown that an open pond can be used to grow algae for biodiesel while simultaneously cleaning significant amounts of wastewater in the process. Peng et al. [21] compare open ponds to photobioreactors in terms of growth rates, dissolved oxygen, and other important growth conditions. Jorquera et al. [22] did a comparison between flat plate photobioreactos, horizontal tubular photobioreactors, and open ponds. For one particular algae, they found that the net energy produced could be greater than 1 (more energy produced than energy consumed) for both flat plate photobioreactors and open ponds. Although this is just one study, it does show that algae holds potential in both a photobioreactor and open pond scheme.

The final growth system being examined is Algal Turf Scrubbers $^{\text {TM }}$ (ATS). ATS typically have the lowest growth potential because they use natural mixed culture algae, but they also tend to have the lowest cost and environmental impact. Hydromentia [23], which to date has been focused mainly on nutrient control in wastewater, uses an ATS with a mixed culture, naturally occurring in a lake or stream, to 
Table 1. Comparison of different algae growth technologies

\begin{tabular}{llll}
\hline & $\begin{array}{l}\text { Maximum growth } \\
\text { potential/oil yield }\end{array}$ & Contamination risk & $\begin{array}{c}\text { Capital } \\
\text { investment }\end{array}$ \\
\hline Algal Turf Scrubber ${ }^{\mathrm{TM}}$ & Low-medium & Low & Medium \\
Photobioreactor & High & Low & High \\
Open Pond & Low-medium & High & Low \\
\hline
\end{tabular}

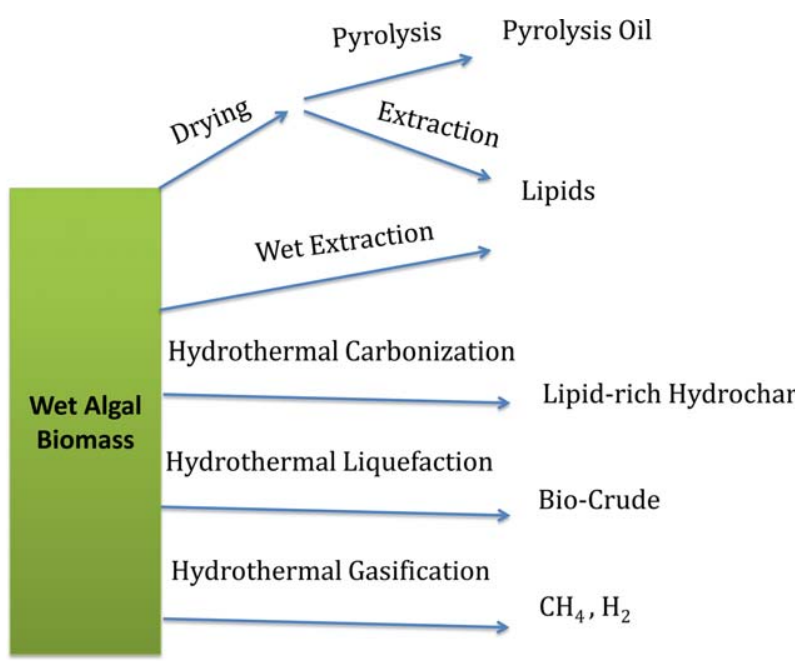

Figure 3. Illustration of different options for converting algal biomass into biofuel intermediates. [Color figure can be viewed in the online issue, which is available at wileyonlinelibrary.com.]

remove nitrogen and phosphorus from water. Just recently, this approach has been combined with biofuel production [24]. Jernigan et al. [2] look at using algae from an ATS raceway for butanol production and studying the long-term storage effects of algae from these types of systems. Other studies have also shown ATS and ATS like systems to have high nutrient removal potential $[25,26]$, but basic economic analysis shows that the in order for the fuel to be produced at a reasonable cost credits for the clean-up must be obtained to mitigate the higher costs of algae growth.

As shown in this discussion, different companies are moving forward with each of these three different approaches for algae growth. The type of system chosen depends on the environment where it is to be used and the specific business model. ATS will make sense in regions where wastewater needs to be treated and the high-carbohydrate, low-lipid biomass provided is attractive. Open ponds will be attractive in places where contamination risk is minimal and thus a monoculture can be maintained in a rather inexpensive environment. Bioreactors will be chosen when extremely high growth rates and perhaps value-added co-products allow for the higher capital costs to be overcome. Finally, we would like to add that the use of oceans or estuaries have potential for algae growth as well as is proposed in the patent "Open Ocean Algae Farm" [27]. However, significant challenges remain in deployment and harvesting of these types of systems.

\section{CONVERSION OF ALGAE TO BIOCRUDE/INTERMEDIATES}

After algae are cultivated, the biomass typically needs to be harvested and dewatered to a more concentrated algal slurry as the next processing step. There are different approaches for accomplishing this concentration which include flocculation, centrifugation, and filtration [28-30].
The wet slurry is then typically either dried or subjected as wet biomass to a solvent extraction step or some sort of thermochemical conversion step to produce a biofuel intermediate [29-31].

Some algal biofuel processes envision working with dry algal biomass as depicted by the top two paths in Figure 3. The dry biomass would be subjected to solvent extraction to remove lipids or subjected to pyrolysis to produce a bio-oil. Pyrolysis can be used to convert algal biomass to a crude bio-oil just as it is routinely used to convert lignocellulosic biomass to bio-oils. These bio-oils tend to have high oxygen content and a high water content, which leads to a modest heating value [32]. Both extraction and pyrolysis produce an intermediate product (lipids, bio-oil) that can then be subsequently converted into a biofuel. There is a large energy penalty associated with drying the wet algal biomass, however. For example, drying a 15 wt \% slurry of algae would require about two-thirds of the heating value of the algal biomass. Any process that includes algae drying will almost certainly fail to be a net energy positive process. That is, the process energy inputs will exceed the energy content of the final biofuel product. There may be some special cases where drying is feasible (e.g., when low-grade waste heat is available from a nearby industry, using solar drying) and there exists a way to circumvent this energy penalty. These instances will probably be the exception rather than the rule, however. Zaimes and Khanna [33] discuss the energy penalty associated with drying more fully in their article in this special issue. We suspect that commercial biorefineries will process wet algal biomass rather than first drying it. Savage [34] provides an overview of the different options that exist for processing wet biomass (e.g., fractionate first or do thermochemical conversion first), and these are outlined in the following paragraphs.

Lipid extraction from wet algal biomass, as included in Figure 3, can be done with hexane or with supercritical $\mathrm{CO}_{2}$ $[35,36]$. The lipids can then be converted to biodiesel by transesterification or to green diesel by catalytic hydrotreating. Though extraction of lipids from wet algal biomass avoids the large energy penalty associated with drying, it is much more difficult than is extraction from the dry biomass [37].

Hydrothermal treatment is a thermochemical conversion step that is well suited for processing wet algal biomass directly. Hydrothermal treatment simply subjects the biomass slurry to elevated temperatures and pressures that are at or above the vapor pressure of water at the reaction temperature so that the water remains in the liquid phase (when subcritical processing temperatures are used). The combined action of the thermal energy and hydrolytic attack of water molecules on the algae biomolecules lead to chemical reactions that convert the biomass to more useful biofuel intermediates. As Figure 3 shows, hydrothermal treatment can be done at moderate temperatures $\left(\sim 200^{\circ} \mathrm{C}\right)$ to produce a solid product (hydrochar), at intermediate temperatures $\left(\sim 300^{\circ} \mathrm{C}-\right.$ $350^{\circ} \mathrm{C}$ ) to produce a crude bio-oil, or at higher temperatures $\left(\sim 400^{\circ}-600^{\circ} \mathrm{C}\right)$ to produce gaseous products. In all cases, hydrothermal treatment also produces an aqueous phase coproduct that can contain organic compounds (and hence some heating value) along with nitrogen and phosphorus 


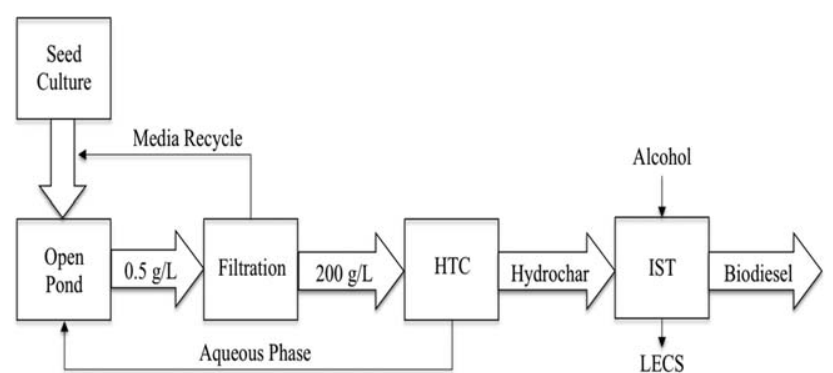

Figure 4. Block flow diagram for making biodiesel from wet algal biomass via HTC [11].

that would need to be recycled as nutrients to the algae growth facility.

Hydrothermal treatment at a temperature of around $200^{\circ} \mathrm{C}$ causes the algae cells to conglomerate and carbonize, thereby forming solid particles that are easy to separate from water via simple filtration [38-41]. The biofuel intermediate produced in this way is a carbonized solid, or hydrochar, which retains nearly all the lipids that were originally resident in the algae. The lipids can then be extracted and separated (e.g., if one desired to recover $\omega$-3-fatty acids as a high-value co-product) or the lipids in the hydrochar can be transesterified directly via uncatalyzed reactions with supercritical alcohol or acid-catalyzed reactions with alcohol at lower temperatures. Levine et al. [11] report on hydrothermal carbonization (HTC). Their report herein is especially significant because it focuses on recycling the aqueous phase co-product to the algae bioreactors, where the $\mathrm{N}$ and $\mathrm{P}$ it contains are taken up by the growing algae cells. Recycling of the nutrients will be essential to ensure the sustainable operation of integrated algae biorefineries.

Hydrothermal liquefaction (HTL) converts all the algae cellular material into a crude bio-oil. This process involves heating the wet algal biomass to around $300^{\circ} \mathrm{C}-350^{\circ} \mathrm{C}$. Under these conditions, the lipid, protein, and carbohydrate biomolecules in the algae cells undergo hydrolysis to form much smaller molecules [42, 43]. The article by Reddy et al. [44] provides experimental results that are representative of those often obtained from HTL studies. The biocrude has a heating value of 35-38 MJ $/ \mathrm{kg}$. The yield of biocrude from HTL typically exceeds the lipid content of the algae, which means that nonlipid components are also converted to biocrude by this process.

There have been several studies with model compounds that provide insight into the chemistry occurring during HTL [45-47]. These studies provided the pathways, kinetics, and in some instances, mechanisms, for the hydrothermal reactions of lipids, amino acids, fatty acid esters, and a chlorophyll derivative. Of course, a drawback to model compound studies is that it can be difficult to know whether the reactions observed for the model compound in isolation are the same as those occurring during algae liquefaction. Experiments with mixtures of model compounds [46, 48] get closer to the behavior of the real system, but experiments that probe algae liquefaction directly would also be informative. To that end, the article by Patel and Hellgardt [49] herein is noteworthy. Crude bio-oils from HTL of algal biomass often contain about $10-15$ wt \% oxygen, with much of this oxygen present as $-\mathrm{OH}$ groups (e.g., in fatty acid, alcohol, or phenolic moieties). The authors' derivatized bio-oil produced at different HTL conditions with a phosphorus-containing moiety. This derivatization allowed the chemical transformations that occurred to the hydroxyl groups during algae liquefaction to be identified with ${ }^{31} \mathrm{P}$ NMR. The authors show clearly, for example, that $-\mathrm{OH}$ groups in fatty acid environments decrease with reaction time whereas $-\mathrm{OH}$ groups in aromatic environments increase.

In addition to carbonization and liquefaction, hydrothermal treatment can also be used to produce a fuel gas containing either primarily methane or primarily hydrogen [50, 51], depending on the reaction conditions and catalyst used (if any). Catalytic gasification is used to produce methane, but effective catalysts such as $\mathrm{Ru}$, can be rapidly deactivated by sulfur atoms present in the biomass. Cherad et al. [12] provide a report on hydrothermal gasification of macroalgae to produce hydrogen and $\mathrm{C}_{1}-\mathrm{C}_{4}$ gases. In addition to producing this valuable gas from a renewable resource, the authors show how the aqueous phase co-product from gasification can be used to facilitate growth and nutrient management for microalgae cultivation.

Though the conversion of algal biomass to a biofuel intermediate (e.g., hydrochar, biocrude) presents new opportunities for making renewable liquid fuels there remain several obstacles to doing so and to doing so in an economically competitive manner. There is a need for research and development work related to better understanding and optimizing each of the conversion pathways. For example, it is not yet clear how the biochemical composition of the algae feedstock influences the yield of biocrude and its properties. Also, the chemistry involved in hydrothermal processing is not yet fully understood. Additionally, there is a need for research into the conversion of the biofuel intermediate into a finished biofuel. Biocrude, for example, contains too much $\mathrm{N}$ and $\mathrm{O}$ and has a viscosity that is too high to permit its direct use as a liquid transportation fuel. There is a need to identify and develop stable, active, and inexpensive catalysts for removing the heteroatoms and tailoring the molecular composition and molecular sizes of the treated biocrude [52].

\section{PROCESSES FOR ALGAL BIOFUEL PRODUCTION}

As is evident from the previous section, there are several different routes for converting algal biomass to intermediate products that can then be further processed into a biofuel. For each of these routes, there are multiple conceptual process configurations that can be envisioned. Figure 4 shows a simplified flowsheet for a process using HTC to make biodiesel from wet algal biomass. The wet algal biomass undergoes carbonization to produce lipid-rich hydrochar, which can then be reacted with ethanol in an in situ transesterification (IST) process to make crude biodiesel. The aqueous phase co-product from carbonization can be recycled to grow more algae. The lipid-extracted carbonized solids (LECS) retain some heating value, so they might be useful as a fuel source. Levine et al. [11] report on various aspects of this conceptual process.

Figure 5 shows a simplified block diagram indicating how an upgraded bio-oil can be produced from wet algal biomass via HTL. The process includes catalytic upgrading to improve the properties of the bio-oil and catalytic hydrothermal gasification to recover energy from the organic material resident in the aqueous phase after liquefaction. The contributions by both Reddy et al. [44] and Patel and Hellgardt [49] provide information about HTL.

Wang et al. [53] report on a process for making a drop-in replacement for hydrocarbon fuels from algae. This team developed a high lipid strain of Dunaliella, an algae species that lacks a cell wall. The algae cells can be lysed using osmotic rupturing, and the lipid bodies float to the top of vessel where they can be recovered. The lipids are then hydrolyzed in water using well-established fat-splitting technology. The fatty acids, which separate naturally from the aqueous phase, then undergo catalytic decarboxylation and hydrogenation to produce $n$-alkanes as the product. The alkanes can then be processed further using existing oil refining technology to produce various liquid fuels. 


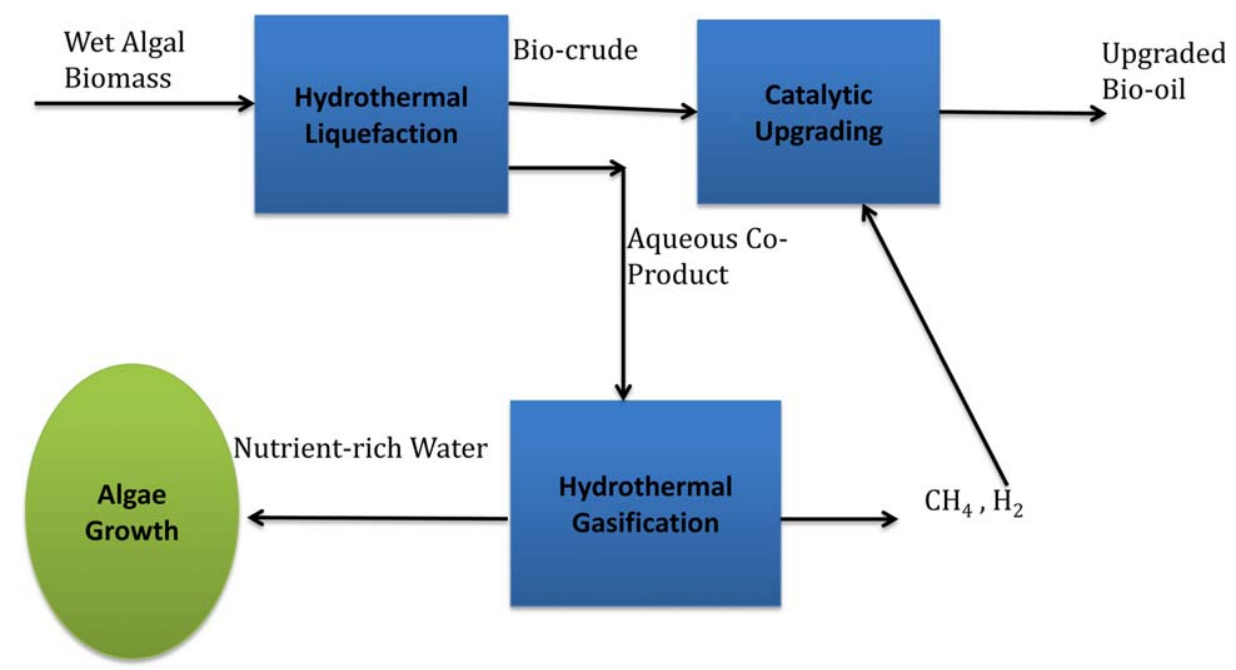

Figure 5. Block flow diagram for algae HTL process. [Color figure can be viewed in the online issue, which is available at wileyonlinelibrary.com.]

The existence of multiple competing processes for converting algal biomass to biofuels clearly points to the significance of process optimization and process assessment (e.g., technoeconomic assessment and life cycle environmental impact assessment) as being key areas of activity in this field [54-56]. One needs to determine the best possible process for each of the different options and then compare the economics and environmental impacts to get a complete understanding of the various tradeoffs involved.

Process optimization for algae biofuels has received limited treatment in the literature. The contribution by Martin and Grossmann [57] focuses on the optimal integration of methanol synthesis with algal biodiesel production. The authors examine a process wherein the glycerol co-product from transesterification is gasified and the syngas so produced is then used for methanol synthesis. The methanol is subsequently used for the synthesis of more biodiesel from algal lipids. This processing approach, which involves internal recycling of methanol, can reduce the need for an external (fossil) source of alcohol in the biodiesel facility. The analyses performed can inform decisions about the best process configuration to choose and the costs of the various options.

In addition to this type of process optimization work, much can be learned from examining the environmental impacts associated with an overall algae biofuel production process. One of the drivers for the development of biofuels is that they provide an opportunity for reducing the $\mathrm{CO}_{2}$ emissions associated with the use of liquid transportation fuels. To assess the extent to which this opportunity is realized requires a life cycle assessment (LCA). Briefly, to perform an LCA one considers specific environmental impacts of interest associated with each step of the biofuel production process (e.g., fertilizer production, algae growth, harvesting, conversion to biofuel intermediate, conversion to final fuel product) and then sums them together to get the overall impact associated with producing a certain quantity (volume or energy content) of biofuel. Such LCA studies can be useful for comparing alternative processes and for identifying the individual processing steps with the greatest environmental impacts. These can then be targeted for additional research or process development to reduce the impacts. The literature contains several LCA studies of biofuel production from algae [54, 55], and these assess various aspects related to environmental sustainability (e.g., water usage, land requirements, greenhouse gas emissions, fossil energy use, eutrophication potential, etc.). Zaimes and Khanna [33] provide an LCA comparison of biodiesel and green diesel production from algal biomass. Their analysis shows that processes that dry the algae and use solvent extraction to recover the lipids from the dry algae will have an unfavorable energy balance and cannot meet the lifecycle greenhouse gas reduction threshold mandated by the renewable fuel standards in the United States. Processes that use wet algal biomass and hydrothermal processes may be advantaged from a life cycle impact perspective.

\section{SUMMARY REMARKS}

The explosion in recent research dealing with the use of aquatic biomass as a feedstock for renewable energy and the myriad environmental implications associated with this potential transition has motivated the preparation of this special issue of Environmental Progress and Sustainable Energy. This introductory article and those that follow show the breadth of the research being conducted with aquatic biomass near the energy-environment nexus. Continued contributions are needed from experts in biology, ecology, environmental engineering, catalytic science and technology, reactor engineering, process systems engineering, and lifecycle and techno-economic assessments.

\section{LITERATURE CITED}

1. Abbasi, T., \& Abbasi, S.A. (2010). Biomass energy and the environmental impacts associated with its production and utilization, Renewable and Sustainable Energy Reviews, 14, 919-937.

2. Jernigan, A., May, M., Potts, T., Rodgers, B., Hestekin, J.A., May, P.I., McLaughlin, J., Beitle, R.R., \& Hestekin, C.N. (2013). Optimal conditions for year round production of butanol from algal carbohydrates, Environmental Progress and Sustainable Energy, in press.

3. Wenzel, W.W. (2009). Rhizosphere processes and management in plant-assisted bioremediation (phytoremediation) of soils, Plant and Soil, 321, 385-408.

4. Mata, T.M., Martins, A.A., \& Caetano, N.S. (2010). Microalgae for biodiesel production and other applications: A review, Renewable and Sustainable Energy Reviews, 14, 217-232. 
5. Groom, M.J., Gray, E.M., \& Townsend, P.A. (2007). Biofuels and biodiversity: Principles for creating better policies for biofuel production, Conversation Biology, 22, 602-609.

6. Griffiths, M.J., \& Harrison, S.T.L. (2009). Lipid productivity as a key characteristic for choosing algal species for biodiesel production, Journal of Applied Phycology, 21, 493-507.

7. Welter, C., Schwenk, J., Kanani, B., Van Blargan, J.V., \& Belovich, J.M. (2013). Minimal media for optimal growth and lipid production of the microalgae Scenedesmus dimorphus, Environmental Progress and Sustainable Energy, in press.

8. Zhao, X., Chi, Z., Rover, M., Brown, R., Jarboe, L., \& Wen, Z. (2013). Microalgae fermentation of acetic acidrich pyrolytic bio-oil: Reducing bio-oil toxicity by alkali treatment, Environmental Progress and Sustainable Energy, in press.

9. Pate, R., Klise, G., \& Wu, B. (2011). Resource demand implications for US algae biofuels production scale-up, Applied Energy, 88, 3377-3388.

10. Wang, X., Shi, L., Zhang, Z., \& Lan, C.Q. (2013). Potential of water hyacinth for phytoremediation in canadian conditions, Environmental Progress and Sustainable Energy, in press.

11. Levine, R.B., Sierra, C.O.S., Hockstad, R., Obeid, W., Hatcher, P.G., \& Savage, P.E. (2013). The use of hydrothermal carbonization to recycle nutrients in algal biofuel production, Environmental Progress and Sustainable Energy, in press.

12. Cherad, R., Onwudili, J.A., Ekpo, U., Williams, P.T., LeaLangston, A.R. (2013). Carmargo-Valergo, M., \& Ross, A.B. Macroalgae supercritical water gasification combined with nutrient recycling for microalgae cultivation, Environmental Progress and Sustainable Energy, in press.

13. Work, V.H., Bentley, F.K., Scholz, M.J., D'Adamo, S.D., Gu, H., Vogler, B.W., Franks, D., Stanish, L.F., Jinkerson, R.E., \& Posewitz, M.C. (2013). Direct photosynethic metabolism toward biocommodities, Environmental Progress and Sustainable Energy, in press.

14. Available at: http://solazyme.com/technology, accessed on April 24, 2013.

15. Kong, B., \& Vigil, D. (2013). Light-limited continuous culture of Chlorella Vulgaris in a Taylor vortex reactor, Environmental Progress and Sustainable Energy, in press.

16. Available at: http://www.environmental-expert.com/ companies/algenol-biofuels-32468, accessed on April 24, 2013.

17. Kumar, K., Dasgupta, C.N., Nayak, B., Lindblad, P., \& Das, D. (2011). Development of suitable photobioreactors for $\mathrm{CO}_{2}$ sequestration addressing global warming using green algae and cyanobacteria, Bioresource Technology, 102, 4945-4953.

18. Slegers, P.M., van Beveren, P.J.M., Wijffels, R.H., van Straten, G., \& van Boxtel, A.J.B. (2013). Scenario analysis of large scale algae production in tubular photobioreactors, Applied Energy, 105, 395-406.

19. Available at: http://www.sapphireenergy.com/, accessed on April 24, 2013.

20. Strum, B.S.M., \& Lamer, S.L. (2011). An energy evaluation of coupling nutrient removal from wastewater with algal biomass production, Applied Energy, 58, 3499-3506.

21. Peng, L., Lan, C.Q., \& Zhang, J. (2013). Evolution, detrimental effects and removal of oxygen in microalga cultures, Environmental Progress and Sustainable Energy, in press.

22. Jorquera, O., Kiperstok, A., Sales, E.A., Embirucu, M., \& Ghirardi, M.L. (2010). Comparative energy life-cycle analyses of micoralgal biomass production in open ponds and photobioreactors, Bioresource Technology, 101, 1406-1413.

23. Available at: http://www.hydromentia.com/, accessed on April 24, 2013.

24. Adey, W.H., Kangas, P.C., \& Mulbry, W. (2011). Algal turf scrubbing: Cleaning surface waters with solar energy while producing a biofuel, BioScience, 61, 434-441.

25. Mulbry, W., Kangas, P., \& Kondrad, S. (2010). Toward scrubbing the bay: Nutrient removal using small algal turf scrubbers on chesapeake bay tributaries, Ecological Engineering, 36, 536-541.

26. Sandefur, H.N., Matlock, M.D., \& Costello, T.A. (2011). Seasonal productivity of a periphytic algal community for biofuel feedstock generation and nutrient treatment, Ecological Engineering, 37, 1476-1480.

27. Albas, J.C., Lacaze, A.D., \& Murphy, K.N. (2012). Open ocean floating algae pond. U.S. Patent \# 8,161,679 B2.

28. Manheim, D. \& Nelson, Y. (2013). Settling and bioflocculation of two species of algae used in wastewater treatment and algae biomass production, Environmental Progress and Sustainable Energy, in press.

29. Brennan, L., \& Owende, P. (2010). Biofuels from microalgae-A review of technologies for production, processing, and extractions of biofuels and co-products, Renewable and Sustainable Energy Reviews, 14, 557-577.

30. Lam, M.K., \& Lee, K.T. (2012). Microalgae biofuels: A critical review of issues, problems and the way forward, Biotechnology Advances, 30, 673-690.

31. Chow, M.C., Jackson, W.R., Chaffee, A.L., \& Marshall, M. (2013). Thermal treatment of algae for production of biofuel, Energy Fuels, 27, 1926-1950.

32. Yoon, J.B., Ryu, C., Jeon, J.K., Park, J., Suh, D.J., Suh, Y.W., Chang, D., \& Park, Y.K. (2011). The characteristics of bio-oil produced from the pyrolysis of three marine macroalgae, Bioresource Technology, 102, 3512-3520.

33. Zaimes, G.G., \& Khanna, V. (2013). Environmental sustainability of emerging algal biofuels: A comparative life cycle evaluation of algae biodiesel and renewable diesel, Environmental Progress and Sustainable Energy, in press.

34. Savage, P.E. (2012). Algae under pressure and in hot water, Science, 338, 1039-1040.

35. Soh, L., \& Zimmerman, J. (2011). Biodiesel production: The potential of algal lipids extracted with supercritical carbon dioxide, Green Chemistry, 13, 1422-1429.

36. Radaelli, G., \& Fleischer, D. (2010). Systems and methods for extracting lipids from wet algal biomass. U.S. Patent Application Publication Number: US 2010/0317088 A1.

37. Cabral, J.M.S., Coelho, J.P., Fernandes, H.L., Mendes, R.L., Novais, J.M., Palavra, A.F., \& Reis, E.C. (1995). Supercritical $\mathrm{CO}_{2}$ extraction of carotenoids and other lipids from Chlorella Vulgaris, Food Chemistry, 53, 99-103.

38. Levine, R.B., Pinnarat, T., \& Savage, P.E. (2010). Biodiesel production from wet algal biomass through in situ lipid hydrolysis and supercritical transesterification, Energy Fuels, 24, 5235-5243.

39. Levine, R.B., Bollas, A., \& Savage, P.E. (2013). Process improvements for the supercritical in situ transesterification of carbonized algal biomass, Bioresource Technology, 136, 556-564.

40. Heilmann, S.M., Davis, H.T., Jader, L.R., Lefebvre, P.A., Sadowsky, M.J., Schendel, F.J., von Keitz, M.G., \& Valentas, K.J. (2010). Hydrothermal carbonization of microalgae, Biomass and Bioenergy, 34, 875-882.

41. Heilmann, S.M., Jader, L.R., Harned, L.A., Sadowsky, M.J., Schendel, F.J., Lefebvre, P.A., von, K., Marc, G., \& Valentas, K.J. (2011). Hydrothermal carbonization of microalgae II. Fatty acid, char, and algal nutrient products, Applied Energy, 88, 3286-3290. 
42. Biller, P., \& Ross, A.B. (2012). Hydrothermal processing of algal biomass for the production of biofuels and chemicals, Biofuels, 3, 603-623.

43. Valdez, P.J., Nelson, M.C., Wang, H.Y., Lin, X.N., \& Savage, P.E. (2012). Hydrothermal liquefaction of Nannochloropsis sp.: Systematic study of process variables and analysis of the product fractions, Biomass Bioenergy, 46, 317-331.

44. Reddy, H.K., Muppaneni, T., Rastegary, J., Shirazi, S., Ghassemi, A., \& Deng, S. (2013). Hydrothermal extraction and characterization of bio-crude oils from wet chlorella Sorokiniana and Dunaliella Tertiolecta, Environmental Progress and Sustainable Energy, in press.

45. Changi, S., Brown, T.M., \& Savage, P.E. (2012). Reaction kinetics and pathways for phytol in high-temperature water, Chemical Engineering Journal, 189-190, 336-345.

46. Changi, S., Zhu, M., \& Savage, P.E. (2012). Hydrothermal reaction kinetics and pathways of phenylalanine alone and in binary mixtures, ChemSusChem, 5, 1743-1757.

47. Changi, S., Matzger, A., \& Savage, P.E. (2012). Hydrothermal kinetics and pathways for a model algal phospholipid, Green Chemistry, 14, 2856-2867.

48. Kruse, A., Maniam, P., \& Spieler, F. (2007). Influence of proteins on the hydrothermal gasification and liquefaction of biomass. 2. Model compounds, Industrial Engineering and Chemistry Research, 46, 87-96.

49. Patel, B., \& Hellgardt, K. (2013). Hydrothermal upgrading of algae paste: Application of ${ }^{31} \mathrm{P}$ NMR, Environmental Progress and Sustainable Energy, in press.

50. Guan, Q., Wei, C., \& Savage, P.E. (2012). Hydrothermal gasification of Nannochloropsis sp. with Ru/C, Energy Fuels, 26, 4575-4582.
51. Stucki, S., Vogel, F., Ludwig, C., Haiduc, A.G., \& Brandenberger, M. (2009). Catalytic gasification of algae in supercritical water for biofuel production and water capture, Energy and Environmental Science, 2, 535-541.

52. Duan, P., \& Savage, P.E. (2011). Upgrading of crude algal bio-oil in supercritical water, Bioresource Technology, 102, 1899-1906.

53. Wang, W.-C., Allen, E., Campos, A.A., Cade, R., Dean, L., Immer, J., Mixson, S., Srirangan, S., Sauer, M.L., Schreck, S., Sun, K., Thapaliya, N., Wilson, C., Burkholder, J., Grunden, A., Lamb, H., Sederoff, H., Stikeleather, L., \& Roberts, W. (2013). Dunaliella marine microalgae to drop-in replacement liquid transportation fuel, Environmental Progress and Sustainable Energy, in press.

54. Clarens, A.F., Resurreccion, E.P., White, M.A., \& Colosi, L.M. (2010). Environmental life cycle comparison of algae to other bioenergy feedstocks, Environmental Science and Technology, 44, 1813-1819.

55. Frank, E., Elgowainy, A., Han, J., \& Wang, Z. (2012). Life cycle comparison of hydrothermal liquefaction and lipid extraction pathways to renewable diesel from algae, Mitigation and Adaptation Strategies for Global Change, 18, 1-22.

56. Davis, R., Aden, A., \& Pienkos, P.T. (2011). Techno-economic analysis of autotrophic microalgae for fuel production, Applied Energy, 88, 3524-3531.

57. Martin, M., \& Grossmann, I.E. (2013). Towards the optimal integrated production of biodiesel with internal recycling of methanol produced from glycerol, Environmental Progress and Sustainable Energy, in press. 